\title{
Solar System Exploration Augmented by In-Situ Resource Utilization: Human Planetary Base Issues for Mercury and Saturn
}

\author{
Bryan Palaszewski* \\ NASA John H. Glenn Research Center \\ Lewis Field \\ MS 5-10 \\ Cleveland, $\mathrm{OH} 44135$ \\ (216) 977-7493 Voice \\ (216) 433-5802 FAX \\ bryan.a.palaszewski@nasa.gov \\ Fuels and Space Propellants Web Site: \\ http://www.grc.nasa.gov/WWW/Fuels-And-Space-Propellants/foctopsb.htm
}

Human and robotic missions to Mercury and Saturn are presented and analyzed with a range of propulsion options. Historical studies of space exploration, planetary spacecraft, and astronomy, in-situ resource utilization (ISRU), and industrialization all point to the vastness of natural resources in the solar system. Advanced propulsion benefitted from these resources in many ways. While advanced propulsion systems were proposed in these historical studies, further investigation of nuclear options using high power nuclear thermal and nuclear pulse propulsion as well as advanced chemical propulsion can significantly enhance these scenarios. Updated analyses based on these historical visions are presented. Nuclear thermal propulsion and ISRU enhanced chemical propulsion landers are assessed for Mercury missions. At Saturn, nuclear pulse propulsion with alternate propellant feed systems and Saturn moon exploration with chemical propulsion and nuclear electric propulsion options are discussed. Issues with using in-situ resource utilization on Mercury missions is discussed. At Saturn, the best locations for exploration and the use of the moons Titan and Enceladus as central locations for Saturn moon exploration is assessed.

Nomenclature

$\begin{array}{ll}3 \mathrm{He} & \text { Helium } 3 \\ \text { 4He } & \text { Helium (or Helium 4) } \\ \text { AMOSS } & \text { Atmospheric mining in the outer solar system } \\ \text { ASC } & \text { Aerospacecraft (for atmospheric mining) } \\ \text { CC } & \text { Closed cycle } \\ \text { delta-V } & \text { Change in velocity }(\mathrm{km} / \mathrm{s}) \\ \text { GCR } & \text { Gas core rocket } \\ \text { GTOW } & \text { Gross Takeoff Weight } \\ \text { H2 } & \text { Hydrogen } \\ \text { He } & \text { Helium 4 } \\ \text { ITV } & \text { Interplanetary transfer vehicle } \\ \text { ISRU } & \text { In Situ Resource Utilization } \\ \text { Isp } & \text { Specific Impulse }(\mathrm{s}) \\ \text { K } & \text { Kelvin } \\ \text { kWe } & \text { Kilowatts of electric power } \\ \text { LEO } & \text { Low Earth Orbit }\end{array}$

* Leader of Advanced Fuels, AIAA Associate Fellow 


$\begin{array}{ll}\text { MESSENGER } & \text { Mercury Space Surface ENvironment, GEochemistry, and Ranging } \\ \text { MT } & \text { Metric tons } \\ \text { MWe } & \text { Megawatt electric (power level) } \\ \text { NEP } & \text { Nuclear Electric Propulsion } \\ \text { NPP } & \text { Nuclear Pulse Propulsion } \\ \text { NTP } & \text { Nuclear Thermal Propulsion } \\ \text { NTR } & \text { Nuclear Thermal Rocket } \\ \text { OC } & \text { Open cycle } \\ \text { O2 } & \text { Oxygen } \\ \text { ppb } & \text { Parts per billion }\end{array}$

\section{Introduction}

Human and robotic missions have been planned for targets throughout the solar system. Both types of missions can benefit greatly from the resources available from the planets and /or their moons (Refs. 1-15). These benefits include water on many of the outer planet moons and large asteroids. With this water, oxygen / hydrogen rocket propulsion systems can be fueled, breathing oxygen can be extracted, and other life support functions (cooling fluids, etc.) can be facilitated. In addition, the atmospheres of many planets have ready reserves of gases for propellant production. Carbon dioxide on Mars can be separated into oxygen and carbon monoxide or, with small amounts of hydrogen, methane can be produced. The outer planets offer enormous amounts of energetic gases such as hydrogen, helium $3(3 \mathrm{He})$, methane, ethane, and ammonia. By using these in-situ resources, robotic precursor missions can double or triple their payloads to the surface and return double or triple the samples from the solar system targets. Without in-situ resource utilization (ISRU), solar system exploration will be exceedingly limited. For future large scale human missions, the possibilities of ISRU for human exploration and settlement offer the best opportunities for sustainability and success.

\section{Human Exploration Options}

In the 1950's, 1960's, 1970's, and 1980's, ambitious robotic and human mission were planned, spanning from Mercury to the outermost reaches of the solar system (Refs. 1-15). While investments in robotic missions have continued, human exploration of the solar system has awaited new invigorating steps. While more ambitious lunar and Mars missions are in the early step-wise planning stages, many cost barriers have prevented their implementation. Future human missions to other destinations such as Mercury and Saturn will also require longterm investments. Currently, Mercury and Saturn have robotic missions returning invaluable data on those planets and their environs (Refs. 16 to 20). These data have provided insights that will ensure the success of future missions. With its proximity to the Sun, Mercury has extremely high temperatures and missions requires special high heat flux considerations for long-term human visits or bases. In contrast, temperatures at Saturn and its moons require designs for cryogenic environments.

\section{A. Mission targets}

The Mercury landing missions are focused on northern polar targets (Refs. 16, 17. And 18). Permanently shadowed craters in these northern polar regions on Mercury contain water ice (Ref. 16, 17, and 18). With this water ice, ISRU factories can produce the oxygen and hydrogen for ascent and descent lander propulsion and hydrogen for the return to Earth on the orbiting NTP vehicle.

The targets at Saturn are primarily its moons (Titan, Mimas, Enceladus, Iapetus, etc.), its atmosphere, and its ring system (Refs. 19 and 20). Atmospheric mining in the outer solar system (AMOSS) has been assessed for Saturn missions (Ref. 35). Due to the extreme atmospheric environmental conditions at Saturn, AMOSS operations there 
are not recommended. In addition, the delta- $\mathrm{V}$ to extract the propellants from the atmosphere and transport it to a moon or other location is quite prohibitive. Alternatively, performing AMOSS at Uranus and transporting the propellant to a Saturn target (Titan, etc.) has been assessed and is more practical than AMOSS at Saturn and greatly reduces the delta-V required, thus reducing the overall system complexity. Also, extracting propellants from the more-benign Uranus environment also improves vehicle safety (Ref. 35).

\section{Human Space Vehicles and Missions}

Space vehicle engine performance, propulsion mass scaling and delta-V estimates were used to predict the LEO masses of both Mercury and Saturn exploration vehicles. LEO mass estimates for extremely high energy missions were assessed. Several ISRU options were investigated at Mercury and Saturn. Landers for one-way and round trip Mercury missions and landers for Saturn's moons are also investigated. Orbital transfer vehicle (OTV) masses were also estimated for Saturn moon missions, with transfers from one moon to another.

\section{A. Mercury Missions}

A human round trip mission to Mercury was assessed. The mission $\Delta \mathrm{V}$ values for the round trip Mercury missions were derived from the literature (Refs. 21 to 25). The highest $\Delta \mathrm{V}$ case was selected from this data: an Earth departure delta- $\mathrm{V}$ of $5.2 \mathrm{~km} / \mathrm{s}$, a Mercury arrival $\Delta \mathrm{V}$ of $10.9 \mathrm{~km} / \mathrm{s}$ and a Mercury departure $\Delta \mathrm{V}$ of $8.7 \mathrm{~km} / \mathrm{s}$ (Ref. 12). At Earth, a capsule enters the atmosphere to return the crew directly to Earth (Ref. 12). The capsule's mass is $4,350 \mathrm{~kg}$; the round trip time is 585 days with a 40 -day stay time at Mercury. In this case, the vehicle does not land on Mercury (Ref. 12). The LEO masses of both chemical propulsion and nuclear thermal propulsion vehicles were estimated. Figure 1 compares the LEO masses for 2 types of chemical propulsion systems (with the differing tankage mass assumptions noted below) and 2 nuclear thermal propulsion (NTP) systems. The interplanetary chemical propulsion systems used tankage dry mass coefficients of 3\% and 5\% of the total propellant mass in the tankage. In many cases, these dry masses may be deemed to be optimistically low; however, they allow some relative comparison of the chemical propulsion and the nuclear mission cases. The chemical propulsion transfer vehicles used 3 stages, while the NTP stages, with the higher dry mass coefficient, required 6 stages. With the NTP vehicles, each of the three large interplanetary maneuvers were split equally between the 2 stages for each of the three maneuvers.

The NTP vehicles' dry mass was 33\% of the propellant mass (Ref. 34). This is a more conservative assumption than was used in Ref. 32. In current NTP designs, an $I_{\text {sp }}$ of 900 seconds is nominally used. Somewhat lower $\mathrm{I}_{\mathrm{sp}}$ values were used for these missions: 800 and 850 seconds, respectively (Ref. 12). These lower $I_{\mathrm{sp}}$ values were assumed given the high heat flux environment of Mercury and the degraded $\mathrm{I}_{\mathrm{sp}}$ values would reflect the added propellant used for propellant cooling and/or refrigeration. The chemical propulsion systems required between 17,150 MT and 31,230 MT to accomplish the mission. The NTP vehicles required approximately an order of magnitude less mass in LEO: 3,900 MT to 2,800 MT. Based on our prior analysis, the stage and lander mass was estimated with a mass scaling equation (Refs. 21 to 25 ).

$\mathrm{M}_{\text {dry,stage }}(\mathrm{kg})=\mathrm{M}_{\text {dry,coefficient }} \bullet \mathrm{M}_{\mathrm{p}}(\mathrm{kg})$

where:

$\mathrm{M}_{\text {dry,stage }}=$ the stage dry mass, including residual propellant $(\mathrm{kg})=$

$\mathrm{M}_{\mathrm{dry}, \text { coefficient }}=$ the B mass coefficient ( $\mathrm{kg}$ of tank mass / $\mathrm{kg}$ of usable propellant mass)

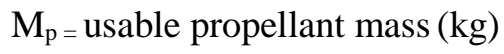


A Mercury landing vehicle mass was also estimated; the one-way $\Delta \mathrm{V}$ for the lander was $3.5 \mathrm{~km} / \mathrm{s}$. The ascent $\Delta \mathrm{V}$ was also $3.5 \mathrm{~km} / \mathrm{s}$ (Ref. 22). These $\Delta \mathrm{V}$ values accommodate approximately $19 \%$ for gravity losses for each maneuver; this gravity loss $\Delta \mathrm{V}$ is added to the orbital velocity for a $100 \mathrm{~km}$ orbit which is $2.945 \mathrm{~km} / \mathrm{s}$. The lander $\mathrm{I}_{\mathrm{sp}}$ was 480 seconds. The higher $\mathrm{I}_{\mathrm{sp}}$ was chosen for the lander as the engine used a higher engine expansion ratio than the interplanetary transfer vehicle. The smaller engine size would allow a higher expansion ratio, given the typical volume constraints for space vehicles. The dry mass coefficient was $20 \%$ of the total propellant load. While the Mercury missions will likely require more aggressive thermal control (propellant shielding, cooling, etc.), that thermal control system mass is accommodated in the payload mass of the vehicle. The payload delivered to the surface was 10 MT. Figure 2 compares the mass in LEO of a one-way lander and a round trip lander. The masses were approximately 140 MT for the round trip lander and 27 MT for the one-way lander. Thus, using ISRU on the surface of Mercury to replenish the lander's propellant would allow a savings of 113 MT on this mission. Additional analyses are needed to investigate the mass reductions for the interplanetary transfer vehicle to carry the lander to Mercury. Another option would be to carry 5 landers to Mercury rather than carry simply one lander; many more permanently shadowed craters could then be visited on one mission. The interplanetary vehicle carrying the 5 landers could be sent on a lower energy trajectory than the human flights, thus saving additional mass launched into LEO in the overall Mercury architecture.

Using Mercury resources to augment the human missions was investigated. An ISRU system's effects on reducing the LEO mass (see Table 1 for details of the NTP-1 and NTP-2) was analyzed. For the NTP-1 and NTP-2 systems, cases were computed where the Mercury departure $\Delta \mathrm{V}$ propellant was supplied at Mercury. The Mercury departure stages are brought from Earth with no propellant. Hydrogen would be produced from the water at the northern polar craters, and transported to orbit. For the NTP-1 case, 104 MT of hydrogen would be transported to orbit. With NTP-2, the propellant mass required in Mercury orbit is $90 \mathrm{MT}$. With the in-situ hydrogen production, the LEO mass of the NTP-1 case is reduced from 3,892 MT to 1,517 MT, as shown in Figure 1. Similar large LEO mass reductions are enabled for the NTP-2 system; using ISRU, the 2,793 MT LEO mass is reduced to 1,136 MT.

Table IV, V, and VI provide the mass summaries of the NTP-1 and NTP-2 options. The propellant masses and dry masses each stage are noted. The stage 5 and stage 6 propellant masses that would be fueled with Mercury hydrogen ISRU are highlighted. As part of the architecture, Mercury landers would carry the hydrogen needed for the return trip to orbit. For the NTP-1 missions 11 round trip lander flights are needed for refueling. With NTP-2, the round trip lander flights needed are reduced to approximately 10. These numbers of flights do not include any additional hydrogen that may be required for cryogenic chill down of the stages tankage and other propulsion components.

Table 1. Space Vehicle Dry Mass Coefficient and Rocket Engine Specific Impulse $\left(\mathrm{I}_{\mathrm{sp}}\right)$

\begin{tabular}{|l|c|c|}
\hline \multicolumn{1}{|c|}{ Technology } & $\mathbf{I}_{\mathbf{s p}}(\mathbf{s e c})$ & $\mathbf{M}_{\text {dry,coefficient }}(\mathbf{k g} / \mathbf{k g} \mathbf{M p})$ \\
\hline Chemical-1 & 450 & 0.03 \\
\hline Chemical-2 & 450 & 0.05 \\
\hline Chemical lander & 480 & 0.20 \\
\hline NTP-1 & 800 & 0.33 \\
\hline NTP-2 & 850 & 0.33 \\
\hline
\end{tabular}




\section{B. Mercury surface excursion planning}

While the temperature is quite comfortable for human habitation inside the permanently shadowed craters (PSC), excursions will be desirable to other locations. While the temperature can be quite high outside the PSC, short excursion will be possible. Robotic missions with cooling systems can persist for long periods in the sunlit areas. These explorers can provide data on the most attractive locations for sampling, and the need for human exploration. Cooling systems based on the heat pipe based design from MESSENGER can be effective (Ref. 22).

Hopping out of permanently shadowed craters for short periods will be desirable. Hopper spacecraft have been conceived for many planetary missions (Ref. 24). While the hoppers can be used for excursions outside the PSC, flights into the anti-Sun shadowed regions of the Mercury will allow for more extensive planet wide exploration (or in essence, wait until it is night time).

The location of the PSCs on Mercury is in both the northern and southern poles. The data presented in Ref. 16 shows the location of the water ice in the northern polar craters. Due to the solar insolation on one side of the crater, the crater is not filled with water ice. Reference 17 shows the images of the water ice in the crater(s). Based on the photographic, spectral and radar data that has been gathered, the total mass of water on Mercury has been estimated to be over $10^{\wedge} 18$ grams or $10^{\wedge} 12 \mathrm{MT}$ (Ref. 16). Additional resource data gathering (remote sensing) from orbit is likely. References 36 and 37 describe the many steps of ISRU and water ice locations and mapping: surveying, prospecting, mining, and beneficiation, as well as the final utilization.

Placing the Mercury base elements underground is also certainly a possibility. There may be great benefits for caching processed water supplies in underground tanks, rather than relying solely upon the permanent shadow for cooling. On the other hand, Mercury's surface has been seen to wrinkle, implying shrinkage of the surface and the planet and this may threaten underground facilities (Ref. 38).

Base locations or sites for gathering the water ice were addressed. The bases in the PSC will be located near the edge of the ice deposit Locating the base or mining sites at the top (near the crater lip but in the shadow) or the left and right sides of the water ice deposit (and not at the bottom of the crater) were suggested (Ref 39). These sites would provide access to the water ice and remain in the permanently shadowed part of the crater. Potential methods for extracting the water ice are discussed in Refs. 36 and 37. A tent for capturing the water would have a heat source to melt the frozen water ice. A layout for a lunar base is presented in Figure 3 (Ref. 39). A similar layout, all within the PSC may be attractive on Mercury. The photovoltaic array would be placed outside of the shadowed area, allowing for solar power to support the base and ISRU operations.

\section{Mercury lander sizing for exploration}

A series of Mercury surface landers were investigated. The landers would carry payloads either one-way or round trip from orbit to the surface of Mercury, Also, the landers can be used for hopping to other parts of the PSC, or between shadowed craters.

One way lander initial masses are shown in Figure 4. The payload masses were varied over the range from 1, 2, 5, 10 MT. The sizing assumptions for the chemical propulsion landers are found in Table I. The lander for a 1 MT payload has an initial mass of 2.7 MT. For the 5 MT payload, the lander initial mass was 13.5 MT. As noted earlier, the 10 MT payload required a lander initial mass of $27 \mathrm{MT}$. The 1 MT payload missions would be well suited for the initial prospecting of the water ice sites. The larger payload landers would then be used for carrying heavier equipment to the surface: ISRU propellant factory subsystems, rovers, power sources, elements of human habitats, etc. 
The lander initial masses for performing round trip flights from orbit to the surface were estimated for 1, 2, 5, 10 MT. Figure 5 depicts the initial masses. The payload of 1 MT required a lander initial mass of 14 MT; a 70.1 MT lander initial mass is required for a 5 MT payload. The 1 MT payload missions would be well suited for the initial prospecting of the water ice sites and returning of both regolith and water samples to the orbiting science laboratories aboard the NTP transfer vehicle(s). The larger payload landers would then be used for carrying human to the surface and then returning to the orbiting NTP interplanetary transfer vehicle.

\section{Saturn mission studies and results}

Human Jupiter and Saturn mission analyses using nuclear pulse propulsion were conducted in the 1960's and 1970's (Ref. 13, 14, 15). Small nuclear devices (or bomblets) were detonated behind the vehicle and with a combination of 100's of nuclear devices, a massive pusher plate and shock absorbers, the vehicle is accelerated through the needed delta-V. The LEO masses for varying propulsion dry masses and total mission delta-V assumptions were estimated. These missions used propulsion mass scaling that may have been optimistic. Parametric variation of the dry mass was analyzed.

References 13, 14 and 15 provided the details from which the propulsion system mass scaling equations were derived. The A parameter of $358,000 \mathrm{~kg}$ is the mass of the pusher plate and associated shock absorbers for the 20-meter diameter system. The 20-meter diameter system design was used on the outer planet mission analyses conducted in Refs. 14 and 15. The Saturn and the Jupiter mission studies used the same set of propulsion mass scaling equations. The Saturn mission delta-V values were derived from Refs. 13, 14 and 15.

The mass scaling equation was:

$\operatorname{Mdry}(\mathrm{kg})=\mathrm{A}+\mathrm{B} \mathrm{Mp}$

where

Mdry $=$ Propulsion system dry mass including residual propellant $(\mathrm{kg})$

$\mathrm{Mp}=$ Usable propellant mass $(\mathrm{kg})$

$\mathrm{A}=$ fixed propulsion system mass $(\mathrm{kg})$

$\mathrm{B}=$ propellant mass dependent mass $(\mathrm{kg} / \mathrm{kg} \mathrm{Mp})$

The final set of mass scaling equations were:

M,dry $(\mathrm{kg})=358,000+0.01 \mathrm{Mp}$

Also the parameter $\mathrm{B}$ was also varied over a range of values: $\mathrm{B}=0.01,0.02,0.05$ and 0.10 . The NPP space vehicle Isp was 3,000 seconds. While a 3,150 second Isp was used in Ref. 13 and 14, the lower (and more conservative) 3,000 second value was used in later publications (Ref. 15).

Figures 6 and 7 provide the mass estimates for a series of Saturn missions over a range of mission delta-V. Based on the work of Ref. 13, 14, 15, and 26 for human Jupiter and Saturn missions, a range of mission delta-V from $60 \mathrm{~km} / \mathrm{s}$ to $120 \mathrm{~km} / \mathrm{s}$ was used in the calculations. While the highest delta$\mathrm{V}$ values may represent impractically high LEO masses for some space missions, they are presented for comparison and completeness. The same overall mission payload masses were used for human Jupiter 
and Saturn missions, which is approximately 391 MT. That mass includes the landing vehicles, habitat and the other supporting hardware and life support expendables for the crew of 20 persons.

Figures 6 to 7 show the variations in LEO mass for B coefficients of 0.01 and 0.1 . The variation in $B$ coefficient would reflect the variation in the mass of the feed systems required for nuclear pulse unit storage, transfer, and ejection. Reference 26 noted that the B coefficient would likely be 0.01 . However, this mass could easily increase given the complexity of the feed systems and the need for multiple canisters to store the individual nuclear units. Each canister was designed to hold 100's of nuclear bomblet units.

For vehicles delivering a delta-V of $60 \mathrm{~km} / \mathrm{s}$, the LEO masses were 6,000 MT for the case of $\mathrm{B}=0.01$ to $7600 \mathrm{MT}$ for a $\mathrm{B}=0.10$. In many cases, space vehicles experience mass growth during development. As such, a more conservative mass estimate is always good for comparison. The vehicle masses for the highest delta-V cases are over 48,000 MT to 97,000 MT. These LEO masses are unusually high and will require many specialized heavy lift launch vehicles. Reference 30 noted the development of the NEXUS vehicle, a post Saturn V capability of over 450 MT (nearly 1 million lbm) into LEO. Reference 30 noted the need for a NEXUS launch capability of 4 to 8 times that of the Saturn V (implying up to nearly 1,000 MT into orbit). Certainly, high Isp options using fusion propulsion for the interplanetary vehicle would simplify operations and reduce the number of launches to LEO.

Even with an increase launch capability, the number of 1,000 MT payload launches required would likely be higher than 50. This number would also include cryogenic boiloff makeup (for propulsion, life support, science support, etc.), airborne support equipment, and other contingency masses.

Table II. Saturn Space Vehicle Dry Mass Scaling Coefficients and Rocket Engine Specific Impulse $\left(\mathrm{I}_{\mathrm{sp}}\right)$

\begin{tabular}{|l|c|c|}
\hline \multicolumn{1}{|c|}{ Technology } & $\mathbf{I}_{\mathbf{s p}}(\mathbf{s e c})$ & $\begin{array}{c}\mathbf{M}_{\text {dry,coefficient }}(\mathbf{k g} / \mathbf{k g} \mathbf{M p}), \\
\mathbf{A}+\mathbf{B} \mathbf{M p}\end{array}$ \\
\hline NPP (nominal) & 3,000 & $358,000+0.01 \mathrm{Mp}$ \\
\hline NPP (heavy) & 3,000 & $358,000+0.10 \mathrm{Mp}$ \\
\hline $\begin{array}{c}\text { Chemical lander, Titan } \\
\begin{array}{c}\text { Chemical lander, Mimas, Enceladus, } \\
\text { and Iapetus }\end{array}\end{array}$ & 480 & 0.20 \\
\hline
\end{tabular}

\section{E. NPP pusher plate mass}

As noted, the NPP vehicle uses nuclear detonations for the main propulsion. The pusher plate, which absorbs and transmits the explosion energy to the spacecraft, is one of the more massive and important subsystems of the propulsion system. Effects of the nuclear energy deposition may limit the lifetime of the NPP vehicle, so the plate mass influence on the LEO mass was estimated. The pusher plate mass was treated parametrically for a range of $258 \mathrm{MT}$ to $658 \mathrm{MT}$. Reference 35 was used as the baseline: the NPP LEO mass was 5,916 MT and the pusher plate was $358 \mathrm{MT}$. The pusher plate mass was varied from 100 MT below the baseline mass to 300 MT above the baseline mass. Also, the NPP tankage mass fraction was varied from $0.01 \mathrm{MP}$ to $0.10 \mathrm{Mp}$. Figures 8 and 9 depict 
the NPP vehicle mass sensitivity for the varying pusher plate masses. In Figure 8, with the 0.01 Mp tankage mass, the 658 MT pusher plate resulted in an NPP LEO mass of 8,283 MT. The NPP pusher plate mass analyses showed that even with a pusher plate of $658 \mathrm{MT}$, the overall vehicle mass would be below or slightly greater than 10,000 MT. Based on historical space vehicle analyses, a 10,000 MT limit may be acceptable for future propulsion systems. The practical mass limit of future launch vehicles and NPP space vehicles and the on-orbit construction complexity may lead to large scale test programs to verify the lifetime of this very massive nuclear propulsion system.

\section{F. Saturn chemical landers and nuclear electric propulsion (NEP) orbital transfer vehicles (OTVs)}

In exploring the moons of Saturn, a central base of operations is likely preferred. Moving the interplanetary NPP space vehicle from moon to moon would be costly in term of propellant mass. An alternative is the use of small chemical propulsion landers delivered by NEP OTVs. A base location for the exploration was assessed and the surface of several moons was investigated. Titan has often been considered the most likely target for exploration. Titan has an atmosphere of primarily nitrogen and based on gravitational measurements, has an extensive subsurface water ocean approximately $100 \mathrm{~km}$ below the surface. While fascinating in term of geology and the potential for life, and gravity of the moon is high: 0.138 that of Earth. This gravity leads to a high delta-V needed for landing and ascent: $3.17 \mathrm{~km} / \mathrm{s}$ for escape velocity. Table III provides the round trip delta- $\mathrm{V}$ (for launch to escape velocity and return) required for 4 moons of Saturn: Mimas, Enceladus, Titan, and Iapetus. Mimas is the innermost of the major moons; Iapetus is the outermost of the major moons. Enceladus was investigated as it is spewing water into space from its south polar regions. Titan has the highest required delta-V of the 4 moons.

Table III. Lander and OTV mass and delta-V summary (Titan centric)

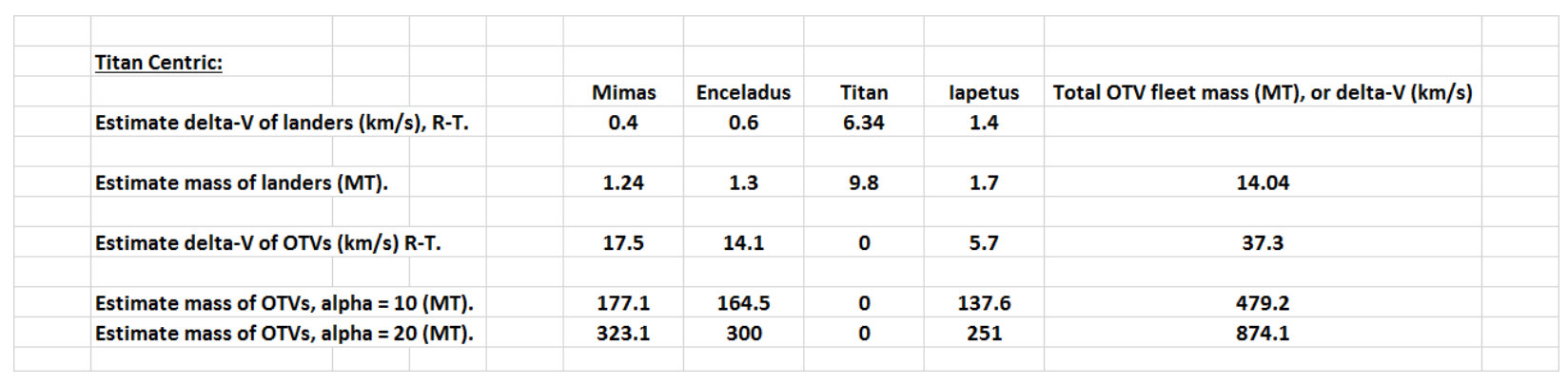

All of these moons have been investigated by the Cassini mission and have a high likelihood of having water ice. Thus each moon could supply water ice for producing oxygen and hydrogen propellants for chemical propulsion and hydrogen propellant for NEP vehicles. Landers on these moons can refuel with oxygen and hydrogen and also provide hydrogen for OTVs to support inter-moon transportation for exploration.

Titan, while having the potential for water resources, those resources may be more difficult to access than the other icy moons. It is likely that the water on Titan may lie $100 \mathrm{~km}$ below the frozen surface which has a temperature of approximately 93 Kelvins (Ref. 19). Ice may also lie in the crust but it may be trapped in clathrates (or caged shaped molecular structures) with methane and or ethane (see the bibliography, Fortes and Stofan (2005)). Given the potential complexity of gathering the water ice on Titan, other icy moons were investigated. Mimas, Enceladus and Iapetus have the potential for large amounts of water ice on their surfaces.

To determine the optimal moon location(s) for gathering water ice, a sensitivity analysis was conducted. The masses of moon landers and OTV for visiting the 4 moons were computed. Figures 10 to 13 provide the lander masses for the 4 moons for a wide range of payload masses. Figure 14 provides the overall fleet mass for the lander and OTV analyses. Two OTV designs were included: the OTVs had a $10 \mathrm{MWe}$ power level with power 
system mass to power ratios (alphas) of 10 and $20 \mathrm{~kg} / \mathrm{kWe}$. The tankage mass fraction was $0.05 \mathrm{Mp}$ and the dry mass of the propulsion system was $21 \mathrm{MT}$. The electric propulsion thruster Isp was 5000 seconds and the thruster efficiency was 50 percent. The delta-V values for the Titan centric OTV transportation system are provided in Table III. The large delta-V values usually preclude a chemical propulsion OTVs, so only NEP OTVs were assessed.

The 4 cases addressed transportation systems centered at each of the 4 moons. For example, a Titan centric transportation system had a lander and OTV to conduct a round trip mission to each moon. Also, three OTVs are needed for each transportation system: one each to one moon, carrying the appropriately sized moon lander. The Titan centric option provided the lowest overall transportation system mass: 479 to 874 MT for Titan. Enceladus provided the $2^{\text {nd }}$ lowest mass: 492 to 888 MT. While Titan required the lowest mass, the complexity of accessing the water ice on Titan may make Enceladus, with its surface-based water ice, a more attractive location.

\section{G. Gravity levels and outer planet moon propellant processing}

In the analyses conducted thus far, the gravity level of the moons has not be addressed in detail. Table IV lists the gravity levels of the major moon of Saturn. Of all of the major moons, Titan is the highest, with $0.138 \mathrm{G}$. All of the other moon have significantly lower gravity levels. Given the nature of historical ISRU operations, this low gravity issue may necessitate the use of a very specialized artificial gravity space base or station for the processing of propellants. This processing may necessitate carrying mined water ice and regolith to orbit and conducting the final processing and purification at the space base. While lifting large amounts of water ice and regolith into orbit may seem extreme, the gravity levels of many of Saturn's moons are quite low: $1.2 \times 10^{\wedge}-2 \mathrm{G}$ for Enceladus. The addition of a space base may require the several hundred tons of additional hardware to Saturn. Given the large payload capacity of the interplanetary NPP space vehicles of 391 MT, this issue may be solved with only a few additional NPP cargo flights.

Table IV. Gravity Levels of Saturn and its Major Moons

\begin{tabular}{|c|r|r|r|r|}
\hline & & & \\
\hline Body & $\mathbf{R}(\mathbf{k m})$ & $\mathrm{m}(\mathrm{kg})$ & $\mathrm{a}\left(\mathrm{m} / \mathrm{s}^{\wedge} \mathbf{2}\right)$ & \multicolumn{1}{c|}{$\mathrm{G}$ level } \\
\hline Saturn & $60,268.0$ & $5.6800 \mathrm{E}+26$ & $1.0434 \mathrm{E}+01$ & $1.066 \mathrm{E}+00$ \\
\hline Mimas & 191.0 & $3.7900 \mathrm{E}+19$ & $6.9321 \mathrm{E}-02$ & $7.079 \mathrm{E}-03$ \\
\hline Enceladus & 248.0 & $1.0800 \mathrm{E}+20$ & $1.1717 \mathrm{E}-01$ & $1.197 \mathrm{E}-02$ \\
\hline Tethys & 526.0 & $6.18 \mathrm{E}+20$ & $1.4904 \mathrm{E}-01$ & $1.522 \mathrm{E}-02$ \\
\hline Dione & 560.0 & $1.1000 \mathrm{E}+21$ & $2.3405 \mathrm{E}-01$ & $2.390 \mathrm{E}-02$ \\
\hline Rhea & 762.0 & $2.3100 \mathrm{E}+21$ & $2.6546 \mathrm{E}-01$ & $2.711 \mathrm{E}-02$ \\
\hline Titan & $2,575.0$ & $1.3455 \mathrm{E}+23$ & $1.3540 \mathrm{E}+00$ & $1.383 \mathrm{E}-01$ \\
\hline lapetus & 712.0 & $1.8100 \mathrm{E}+21$ & $2.3824 \mathrm{E}-01$ & $2.433 \mathrm{E}-02$ \\
\hline
\end{tabular}

\section{Concluding Remarks}

Missions to Mercury and Saturn's moons are hopeful targets for future human missions. At Mercury, polar landing sites will offer important sources of water for soft landings and exploration missions. Using oxygen /hydrogen chemical propulsion and hydrogen powered NTP and ISRU, the water ice can provide capabilities to visit many locations on Mercury with refuelable landers. By refueling the 2 NTP return stages with hydrogen at Mercury, the interplanetary transfer vehicle LEO mass can be reduced from approximately 3,900 MT to 1,520 MT (for the Isp $=800$ seconds cases). At 850 seconds Isp, the LEO mass is reduced from approximately 2800 MT to 1140 MT.

With Saturn, powerful NPP vehicles were assessed. Round trip missions with very short trip times will require enormous masses in LEO: up to 48,000 MT with the most optimistic vehicle dry masses. More conservative 
vehicle tankage designs may require nearly 100,000 MT. Using ISRU for refueling of a one-way mission will reduce the LEO mass to approximately 6,000 MT to 8,000 MT. The NPP pusher plate mass analyses showed that even with a pusher plate of $658 \mathrm{MT}$, the overall vehicle mass would be below or slightly greater than 10,000 MT.

An initial optimization of the OTV and lander fleet needed for small scientific missions to four major moons of Saturn. Titan or Enceladus are the best locations for Saturn moon exploration, requiring the lowest OTV lander fleet mass of the 4 moons that were assessed. Further analyses may reveal an improved location, based on the access to water ice on moon other than Titan and Enceladus. If the outer planet moons gravity is too low, the ISRU processing may require the added mass and complexity of a space based artificial gravity factory.

Both Mercury and Saturn exploration may unlock vast resources from which further new human visions of solar system occupation and settlement. While Mercury has water ice at its poles, water ice is also plentiful on the outer planet moons. New technologies, thought processes, and branches of human civilization may arise from these ambitious exploration missions. Establishing new cradles of humanity will be needed in the far future for our protection as a species, and these far flung exploration targets may be first steps to secure that future.

\section{References}

${ }^{1}$ Ehricke, K. A., "Lunar industrialization and settlement - Birth of poly-global civilization," Lunar Bases and Space Activities of the 21st Century Conference, Houston, TX, Lunar and Planetary Institute, 1985, p. 827-855.

${ }^{2}$ Ehricke, K. A., "Harenodynamic cooling - The use of lunar sand as cooling medium," Acta Astronautica, Vol. 11, June 1984, p. 319-325.

${ }^{3}$ Ehricke, K. A., "Profitability of manufacturing in space in view of lunar industrial development and geo-socio-economic benefits," Manufacturing in space; Proceedings of the Winter Annual Meeting, Boston, MA, November 13-18, 1983, American Society of Mechanical Engineers, 1983, p. 183-198.

${ }^{4}$ Ehricke, K. A., "A socio-economic evaluation of the lunar environment and resources. III Selenospheric economics and cislunar/terrestrial market analysis," IAF PAPER 82-235, International Astronautical Federation, International Astronautical Congress, 33rd, Paris, France, Sept. 27-Oct. 2, 1982, $25 \mathrm{p}$.

${ }^{5}$ Ehricke, K. A., "A socio-economic evaluation of the lunar environment and resources. II Energy for the selenosphere," IAF PAPER 79-A-16, International Astronautical Federation, International Astronautical Congress, 30th, Munich, West Germany, Sept. 17-22, 1979, 25 p.

${ }^{6} \mathrm{Krafft}$ A. Ehricke, A socio-economic evaluation of the lunar environment and resources: I. Principles and overall system strategy," Acta Astronautica, Volume 8, Issues 11-12, NovemberDecember 1981, Pages 1389-1405.

${ }^{7}$ Ehricke, K., "Lunar industries and their value for the human environment on Earth." Acta Astronautica, 1974. Volume 1, pp. 585-622.

${ }^{8}$ Ehricke, K. "Further analyses of the slide lander and of drop delivery systems for improved lunar surface access," Acta Astronautica Volume 10, Number 9, pp. 629 to 650, 1983.

277.

${ }^{9}$ Ehricke, K. A., "Economy of large launch vehicles including orbital labor cost," AIAA 1963-

${ }^{10}$ Ehricke, K., "A comparison of propellants and working fluids for rocket propulsion," American Rocket Society (ARS) Journal, September-October 1953, Volume 23, Number 5, pp. 287-300. 
12 Manning, L. "Comparison of Several Trajectory Modes for Manned and Unmanned Missions to Mercury 1980-2000,” AIAA 67-28, 1967.

${ }^{13}$ Marx, G., "Model study of fuel requirements for fast interplanetary flights using advanced nuclear propulsion systems and refueling at destination," Thesis, Technical University of Berlin (West Germany), In German, May 9, 1967.

${ }^{14} \mathrm{~K}$. EHRICKE, "STUDY OF INTERPLANETARY MISSIONS TO MERCURY THROUGH SATURN WITH EMPHASIS ON MANNED MISSIONS TO VENUS AND MARS 1973/82 INVOLVING CAPTURE," Engineering Problems of Manned Interplanetary Exploration, 1963, AIAA 1963-1514.

${ }^{15}$ Ehricke, K., Perspective and Systems Engineering of Manned Planetary Flight,” AAS 70-037, 1970. In: Space Shuttles and Interplanetary Flight, Volume 28, Advances in Astronautical Sciences, 1970.

MESSENGER at Mercury:

${ }^{16}$ David J. Lawrence et al., "Evidence for Water Ice Near Mercury's North Pole from MESSENGER Neutron Spectrometer Measurements.” Science 339, 292 (2013);

${ }^{17}$ Chabot, N., IMAGING INSIDE MERCURY'S PERMANENTLY SHADOWED CRATERS FIRST IMAGES FROM MESSENGER, Paper 1693, 44th Lunar and Planetary Science Conference (2013).

${ }^{18}$ David A. Paige, MESSENGER Planetary Conference Multimedia Page - MESSENGER Participating Scientist, University of California, Los Angeles, CA. http://messenger.jhuapl.edu/news room/presscon 12 multi.html . With: David A. Paige, et al., "Thermal Stability of Volatiles in the North Polar Region of Mercury," Science, January 18, 2013: Vol. 339, No. 6117, pp. 300-303.

Cassini at Saturn:

${ }^{19}$ G. TOBIE, J.I. LUNINE, J. MONTEUX, O. MOUSIS AND F. NIMMO, “The Origin and Evolution of Titan," in Titan: Interior, Surface, Atmosphere and Space Environment Muller-Wodarg, Griffith, Lellouch and Cravens, eds., Cambridge Univ. Press, pp. 24-50, 2012.

http://www.es.ucsc.edu/ fnimmo/website/Tobie_Titan.pdf .

${ }^{20}$ J.R. Spencer, F. Nimmo, "Enceladus: An active ice world in the Saturn System," Annual Review of Earth and Planetary Sciences 41, 693-717, 2013.

Mercury mission design:

${ }^{21}$ Christopher McLean, "Cryogenic Propellant Depots Design Concepts and Risk Reduction Activities," Future In-Space Operations (FISO), teleconference, March 2, 2011, 303-939-7133, cmclean@ball.com and http://spirit.as.utexas.edu/ fiso/archivelist.htm. 
${ }^{22}$ MESSENGER - Mercury Orbit Insertion (MOI) Press Kit, NASA Headquarters and the Applied Physics Laboratory, Johns Hopkins University, March 2011, http://messenger.jhuapl.edu, http://messenger.jhuapl.edu/news_room/Mercury_PK_TST_Rev7_Web.pdf .

Titan:

${ }^{23}$ Fulchignoni, M., et al. "In situ measurements of the physical characteristics of Titan's environment" Nature 438, pp. 785-791, December 8, 2005.

Hopper:

${ }^{24}$ Linne, Diane L., Barsi, Stephen J., Sjauw En Wa, Waldy K., Landis, Geoffrey A., "Mars Surface Mobility Leading to Sustainable Exploration," AIAA Paper 2012-0806, January 2012.

Space vehicles:

${ }^{21}$ Palaszewski, B., "Metallized Propellants for the Human Exploration of Mars ," NASA-Lewis Research Center, NASA TP-3062, presented at the Case For Mars IV Conference, Boulder, CO, June 48 1990. Also in the AIAA Journal of Propulsion and Power, Vol. 8, No. 6, Nov.-Dec. 1992, pp. 11921199

${ }^{22}$ Bensky, M., "Propulsion requirements for soft landing in extraterrestrial environments," Rocketdyne, NAS7-124, NASA CR-55088, February 1963.

${ }^{23}$ Palaszewski, B., "Atmospheric Mining in the Outer Solar System: Resource Capturing, Storage, and Utilization,” AIAA 2012-3742, July 2012.

${ }^{24}$ Palaszewski, B., "Atmospheric Mining in the Outer Solar System: Issues and Challenges for Mining Vehicle Propulsion,” AIAA 2011-6041, August 2011.

${ }^{25}$ Palaszewski, B., "Lunar Missions Using Advanced Chemical Propulsion: System Design Issues," NASA-Lewis Research Center, NASA TP-3065, AIAA 90-2341, presented at the 26th AIAA/ASME/SAE Joint Propulsion Conference, Orlando, FL, July, 1990, also in AIAA Journal of Spacecraft and Rockets, Vol. 31, No. 3, May-June 1994, pp. 458-465.

Nuclear pulse propulsion:

${ }^{26}$ Ehricke, K., "Interplanetary maneuvers in manned helionautical missions," (1965) AIAA 1965695.

${ }^{27}$ Ehricke, K. A.," Solar Transportation," Presented to the 4th Goddard Memorial Symposium, AM. ASTRONAUTICAL SOC., WASHINGTON, D. C., 15-16 MAR. 1966

28 “A Grand Vision of Man's Role in Colonizing the Universe" by Oyang Teng, LaRouche Youth Movement (Book review) - Marsha Freeman, "Krafft Ehricke's Moon: The Extraterrestrial Imperative,” Technology Editor of Executive Intelligence Review, 2009.

http://www.21stcenturysciencetech.com/Articles 2009/Summer-2009/Extraterrestrial Imperative.pdf 
${ }^{29}$ G. R. Schmidt, J. A. Bonometti, and C. A. Irvine, "Project Orion and Future Prospects for Nuclear Pulse Propulsion,” JOURNAL OF PROPULSION AND POWER, Vol. 18, No. 3, May-June 2002.

${ }^{30}$ Krafft Ehricke, and FREEMAN D'VINCENT, "NEXUS - CONCEPT OF A LARGE REUSABLE LAUNCH VEHICLE,” AIAA 1963-277, 1963.

${ }^{31}$ Williams, Craig H.; Dudzinski, Leonard A.; Borowski, Stanley K.; Juhasz, Albert J., "Realizing "2001: A Space Odyssey": Piloted Spherical Torus Nuclear Fusion Propulsion," NASA/TM2005-213559, AIAA Paper 2001-3805, published 2005.

${ }^{32}$ Palaszewski, B., "Solar System Exploration Augmented by In-Situ Resource Utilization: Human Mercury and Saturn Exploration,” AIAA 2015-1654, January 2015.

${ }^{33}$ Palaszewski, B., "Atmospheric Mining in the Outer Solar System: Aerial Vehicle Mission and Design Issues, AIAA 2015-4078, July 2015

${ }^{34}$ Borowski, S., et al. "7-Launch" NTR Space Transportation Option for NASA's Mars Design Reference Architecture (DRA) 5.0, AIAA 2009-5308, July 2009.

35 Palaszewski, B., "Solar System Exploration Augmented by In-Situ Resource Utilization: Human Mercury and Saturn Propulsion Investigations," AIAA 2016-0717, January 2016.

36 Michael B. Duke, Robert J. Gustafson, and Eric E. Rice, "MINING OF LUNAR POLAR ICE,” Orbital Technologies Corporation, Madison, Wisconsin, AIAA-98-1069

37 Gerald B. Sanders, "SPACE RESOURCE UTILIZATION: TECHNOLOGIES AND POTENTIAL SYNERGISM WITH TERRESTRIAL MINING," Presentation for the Planetary \& Terrestrial Mining Sciences Symposium (PTMSS), Montreal, Canada, May 2015.

38 Alexandra Witze, "Mercury shrinking more than thought," Nature. December 09, 2013, doi:10.1038/nature.2013.14331.

39 Z. Khan, A. Vranis and A. Zavoico, S. Freid, B. Manners, "Power System Concepts for the Lunar Outpost: A Review of the Power Generation, Energy Storage, Power Management and Distribution (PMAD) System Requirements and Potential Technologies for Development of the Lunar Outpost," NASA/TM-2006-214248, DOE/NV/11718-1118, June 2006.

\section{Bibliography}

Mercury:

David A. Paige, Matthew A. Siegler, John K. Harmon, David E. Smith, Maria T. Zuber, Gregory A. Neumann, Sean C. Solomon, "THERMAL STABILITY OF FROZEN VOLATILES IN THE NORTH POLAR REGION OF MERCURY," 43rd Lunar and Planetary Science Conference (2012), Abstract No. 2875.

James L. Dickson, James W. Head, Jennifer L. Whitten, Caleb I. Fassett, Gregory A. Neumann, David E. Smith, Maria T. Zuber, Roger J. Phillips, "TOPOGRAPHIC RISE IN THE NORTHERN SMOOTH PLAINS OF MERCURY: CHARACTERISTICS FROM MESSENGER IMAGE AND ALTIMETRY DATA AND CANDIDATE MODES OF ORIGIN," 43rd Lunar and Planetary Science Conference (2012), Abstract No. 2249. 
Matthieu J. Talpe, Maria T. Zuber, Gregory A. Neumann, Erwan Mazarico, Sean C. Solomon, and Faith Vilas. "CHARACTERIZATION OF THE MORPHOMETRY OF IMPACT CRATERS HOSTING POLAR DEPOSITS IN MERCURY'S NORTH POLAR REGION," 43rd Lunar and Planetary Science Conference (2012), Abstract No. 1600 .

Gregory A. Neumann, John F. Cavanaugh, Xiaoli Sun, Erwan Mazarico, David E. Smith, Maria T. Zuber, Sean C. Solomon and David A. Paige, "DARK MATERIAL AT THE SURFACE OF POLAR CRATER DEPOSITS ON MERCURY," 43rd Lunar and Planetary Science Conference (2012), Abstract No. 2651.

P. S. Cobian, F. Vilas, S. M. Lederer, and N. G. Barlow, "SEARCHING FOR TERRAIN SOFTENING NEAR MERCURY'S NORTH POLE," Lunar and Planetary Science XXXV (2004), Abstract No. 2152.

Kozlova E.A., PROBABLE MODEL OF ANOMALIES IN THE POLAR REGIONS OF MERCURY,” Lunar and Planetary Science XXXV (2004), Abstract No. 1528.

Nadine G. Barlow, Ruth A. Allen and Faith Vilas, "MERCURIAN IMPACT CRATERS: IMPLICATIONS FOR POLAR GROUND ICE,” Icarus, Volume, 141, Number, 2, Oct 1999, pages 94-204.

J. K. Harmon and M. A. Slade, "Radar Mapping of Mercury: Full-Disk Images and Polar Anomalies," SCIENCE, VOL. 258, 23 OCTOBER 1992.

Saturn - Titan:

C. Sotin, K.J. Lawrence, B. Seignovert, J. W. Barnes, R.H. Brown, K.H. Baines, B.J. Buratti, R.N. Clark, and P.D. Nicholson, "FORMATION AND EVOLUTION OF TITAN'S ORGANIC SEAS," Workshop on the Habitability of Icy Worlds, Pasadena, CA, February 5-7, 2014.

G. Tobie, O. Bollengier, A. Lefevre, N. Marounina, J. Monteux, R.-M. Baland, L. Bezacier, H. Amit, S. Carpy, G. Choblet, and O. Grasset1, "FORMATION AND EVOLUTION OF AN INTERNAL WATER OCEAN ON

TITAN," Workshop on the Habitability of Icy Worlds, Pasadena, CA, February 5-7, 2014

BIG IMPACTS AND TRANSIENT OCEANS ON TITAN. K. J. Zahnle, D. G. Korycansky and C. A. Nixon, Workshop on the Habitability of Icy Worlds, Pasadena, CA, February 5-7, 2014.

C.D. Neish, R.L. Kirk, R.D. Lorenz, V.J. Bray, P. Schenk, B.W. Stiles, E. Turtle, K. Mitchell, A. Hayes, and the Cassini RADAR Team, "Crater topography on Titan: Implications for landscape evolution," Icarus 223 (2013), pages 82-90.

J. M. Moore and F. Nimmo, “DOES TITAN'S LANDSCAPE BETRAY THE LATE ACQUISITION OF ITS CURRENT ATMOSPHERE?" 43rd Lunar and Planetary Science Conference (2012), Abstract No. 1248.

R.D. Lorenz, C. Elachi, B. Stiles, R. West2, M. Janssen, R Lopes, E Stofan, F Paganelli, C. Wood, R. Kirk, J Lunine1, S Wall, , and the Cassini RADAR Team, "TITAN'S ELUSIVE LAKES?: PROPERTIES AND CONTEXT OF DARK SPOTS IN CASSINI T.A. RADAR DATA,” Lunar and Planetary Science XXXVI (2005), Abstract No. 1682.

J. Lunine, N. Artemieva, R. Lorenz, and E. Flamini, "NUMERICAL MODELING OF IMPACT CRATERING ON TITAN WITH IMPLICATIONS FOR THE AGE OF TITAN'S SURFACE,” Lunar and Planetary Science XXXVI (2005), Abstract No. 1504. 
M. V. Gerasimov and E. N. Safonova, "IMPACTS OF LARGE METEORITES AS A POSSIBLE SOURCE OF COMPLEX ORGANIC SPECIES ON TITAN,” Lunar and Planetary Science XXXVI (2005), Abstract No. 1066.

Charles A. Wood, Rosaly Lopes, Ellen R. Stofan,, Flora Paganelli, Charles Elachi, and the Cassini RADAR Science Team, "IMPACT CRATERS ON TITAN?: CASSINI RADAR VIEW," Lunar and Planetary Science XXXVI (2005), Abstract No. 1117.

R.M. Lopes, C. Elachi, E. Stofan, F. Paganelli, C. Wood, R. Kirk, R. Lorenz, A.D. Fortes, J. Lunine, S.D. Wall, and the Cassini RADAR Team, "CRYOVOLCANIC FEATURES ON TITAN'S SURFACE AS REVEALED BY THE CASSINI RADAR,” Lunar and Planetary Science XXXVI (2005), Abstract No. 1885.

A. Dominic Fortes and Ellen R. Stofan, "CLATHRATE FORMATION IN THE NEAR-SURFACE ENVIRONMENT OF TITAN.” Lunar and Planetary Science XXXVI (2005), Abstract No. 1123. 


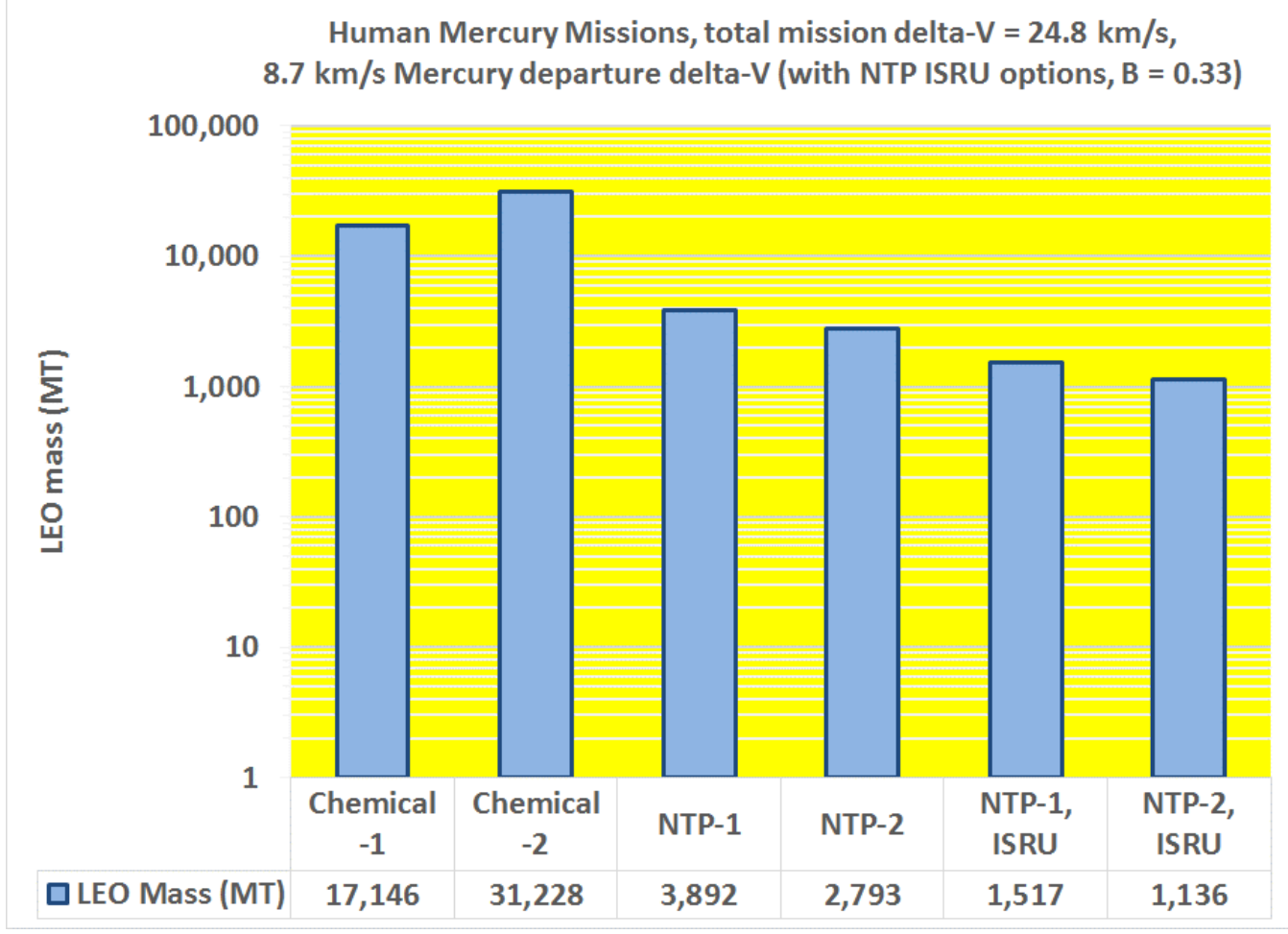

Figure 1. LEO Departure Mass for Human Mercury Missions (Ref 15).

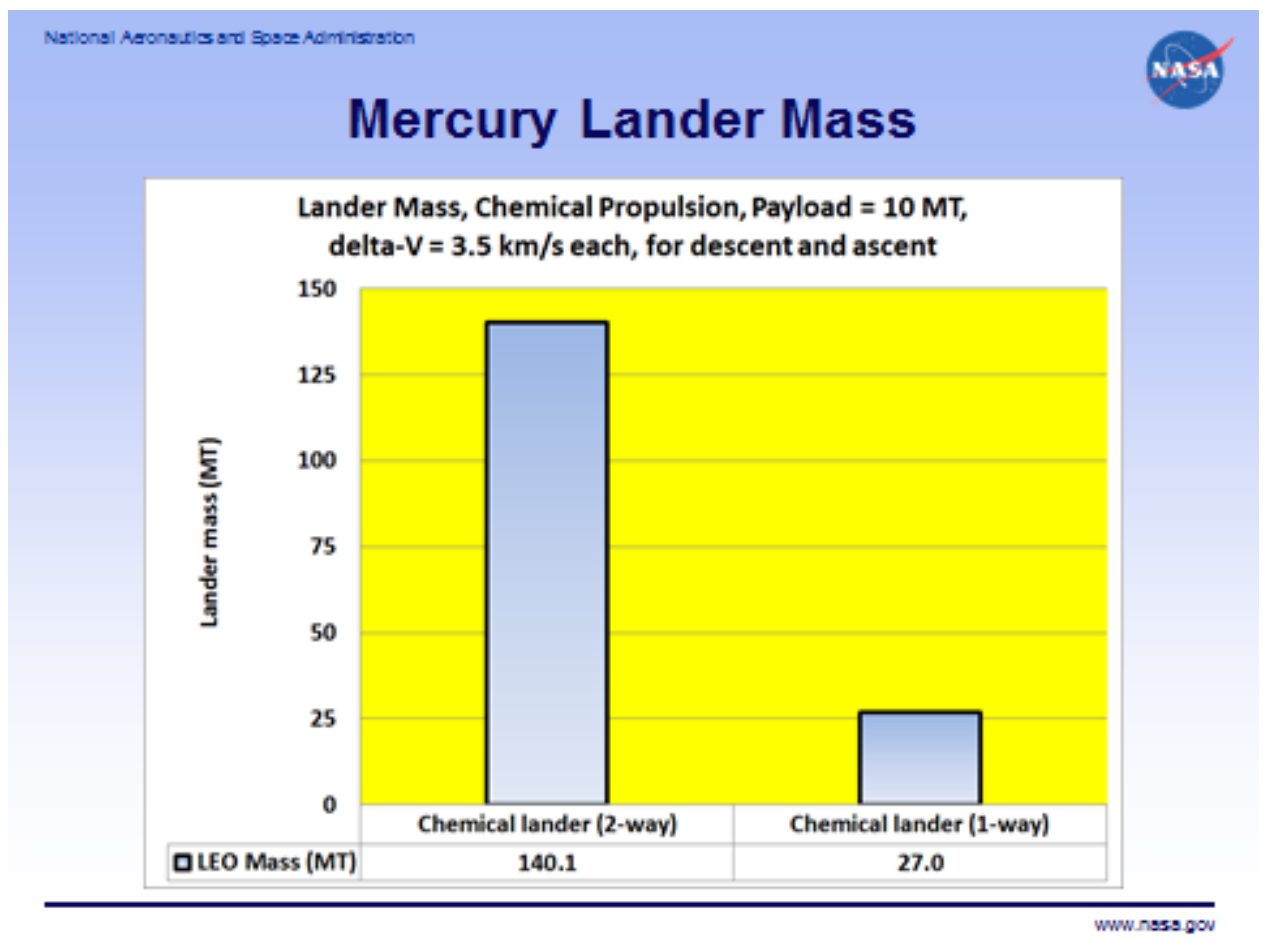

Figure 2. Mercury Lander Mass (Ref. 14). 


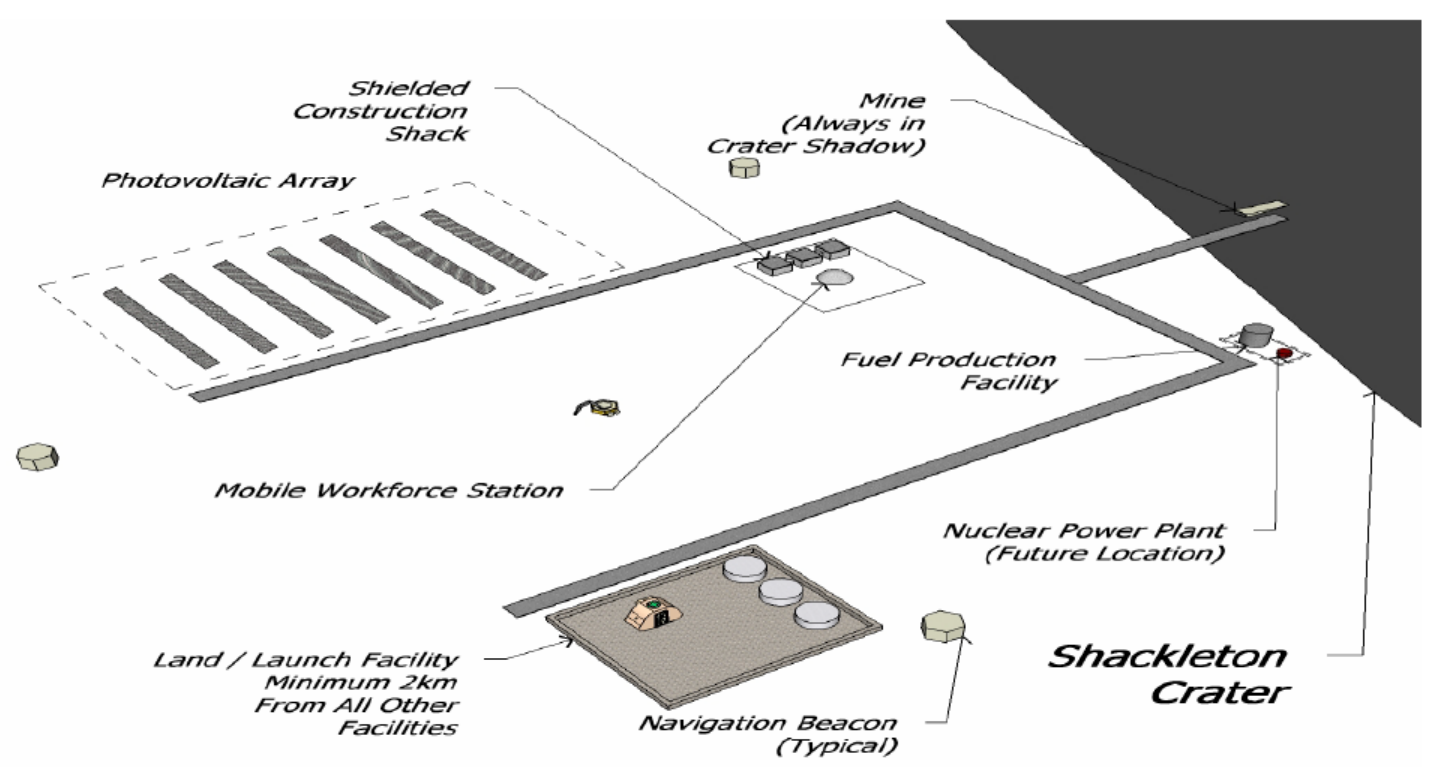

Figure 3. Lunar base site for mining water ice from a PSC.

Ref. - Z. Khan, A. Vranis and A. Zavoico, S. Freid, B. Manners, "Power System Concepts for the Lunar Outpost: A Review of the Power Generation, Energy Storage, Power Management and Distribution (PMAD) System Requirements and Potential Technologies for Development of the Lunar Outpost," NASA/TM-2006-214248, DOE/NV/11718-1118, June 2006.

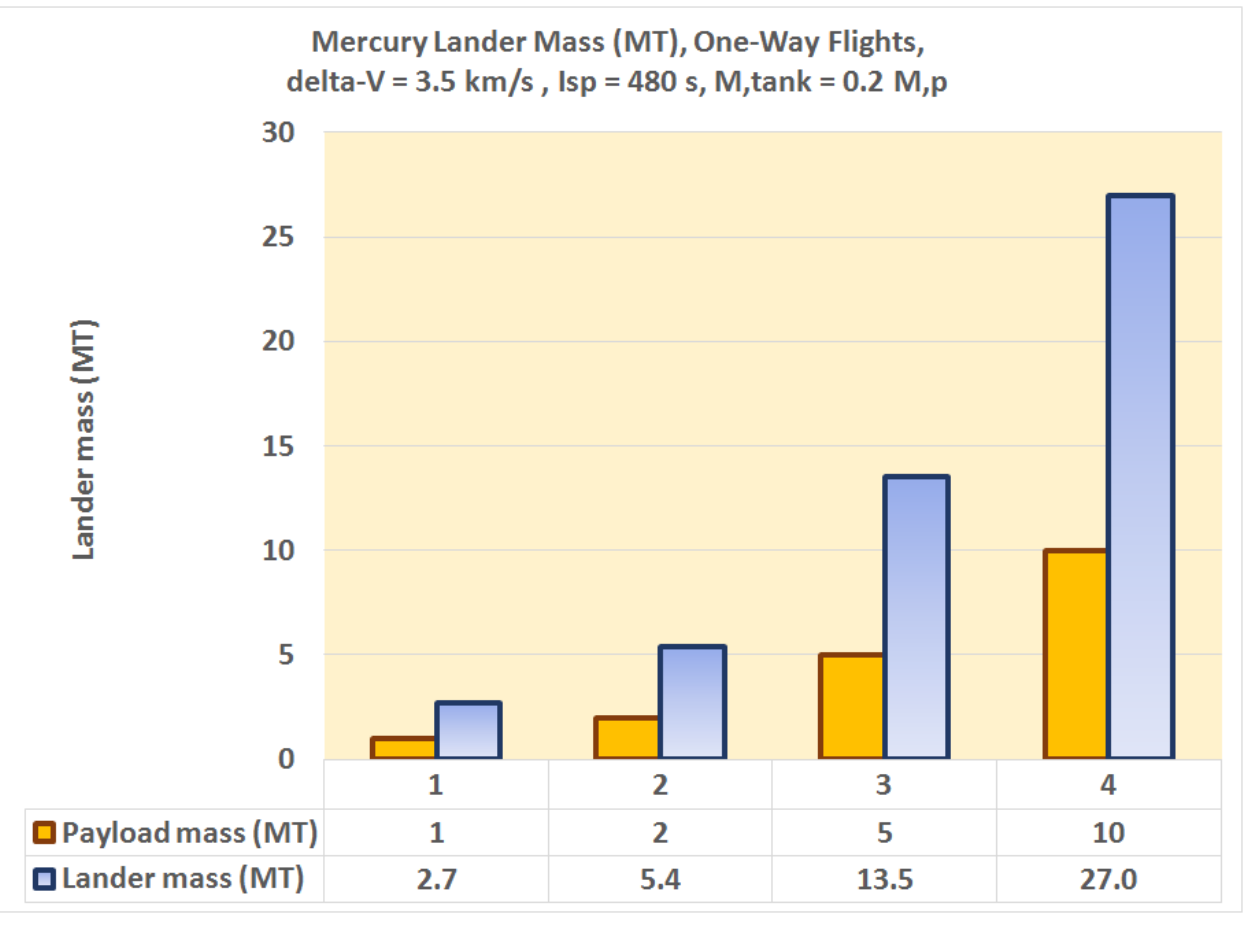

Figure 4. Mercury Lander Mass, one-way flights, with payload masses of 1 to 10 MT. 


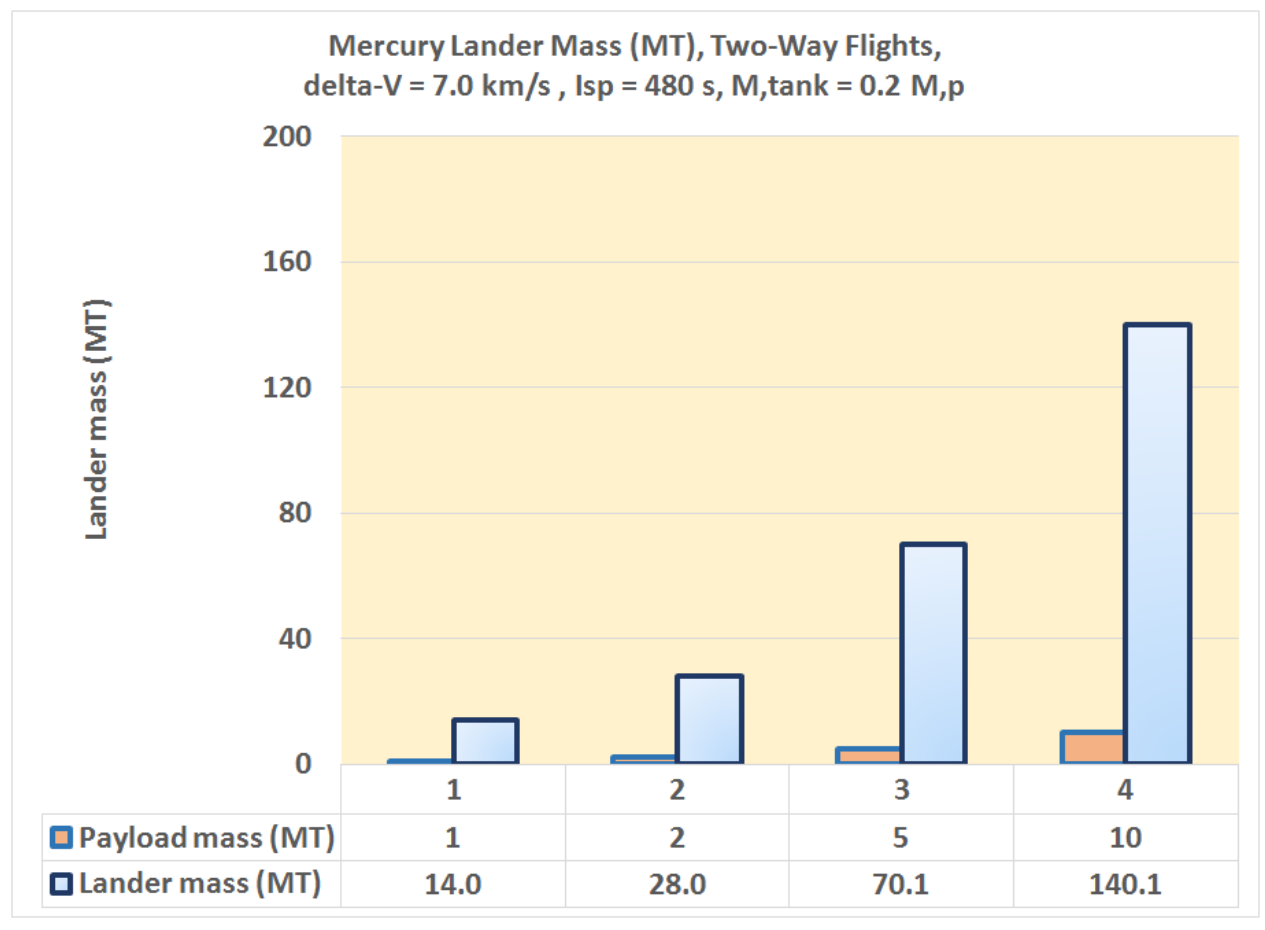

Figure 5. Mercury Lander Mass, round trip flights, with payload masses of 1 to 10 MT.

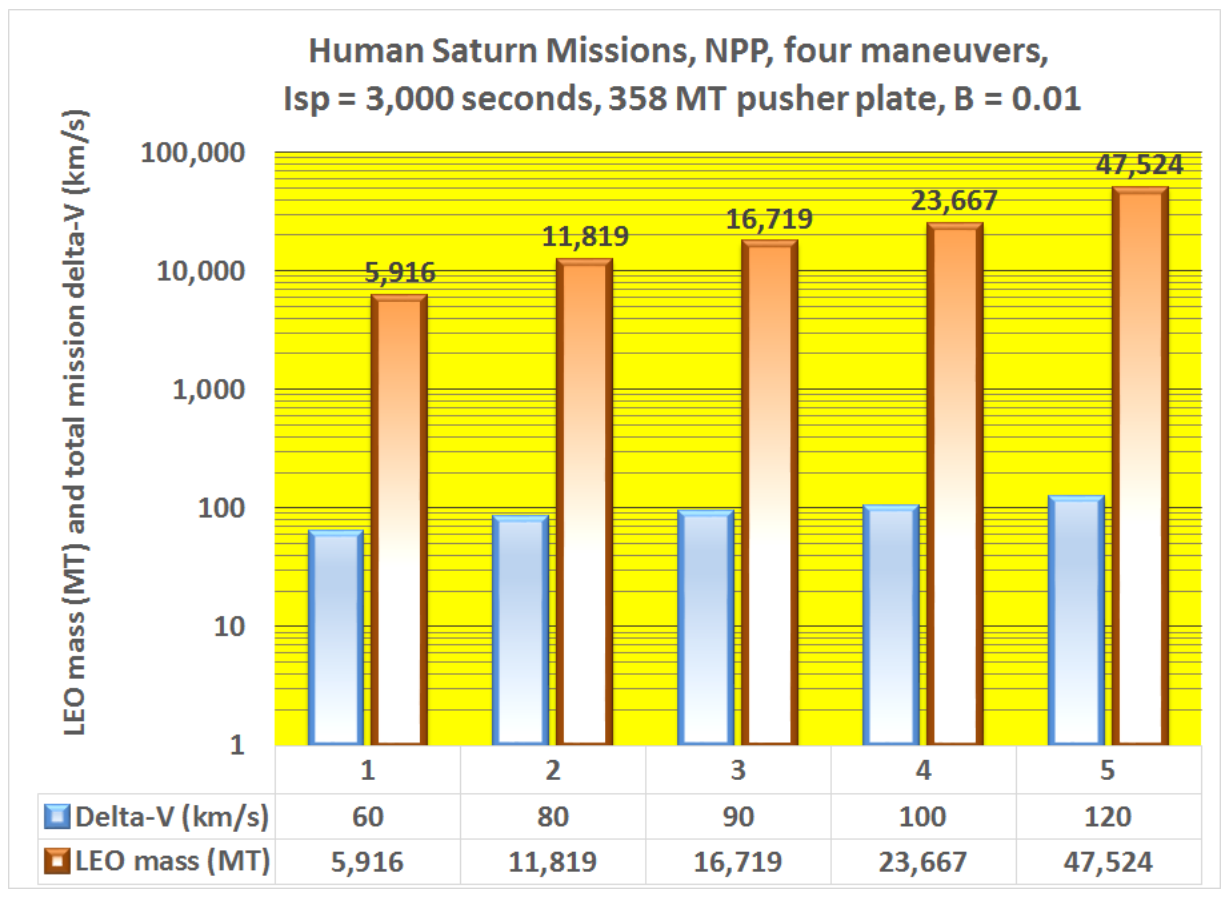

Figure 6. Saturn NPP sizing and mission data, B = 0.01 Mp (Ref. 14). 


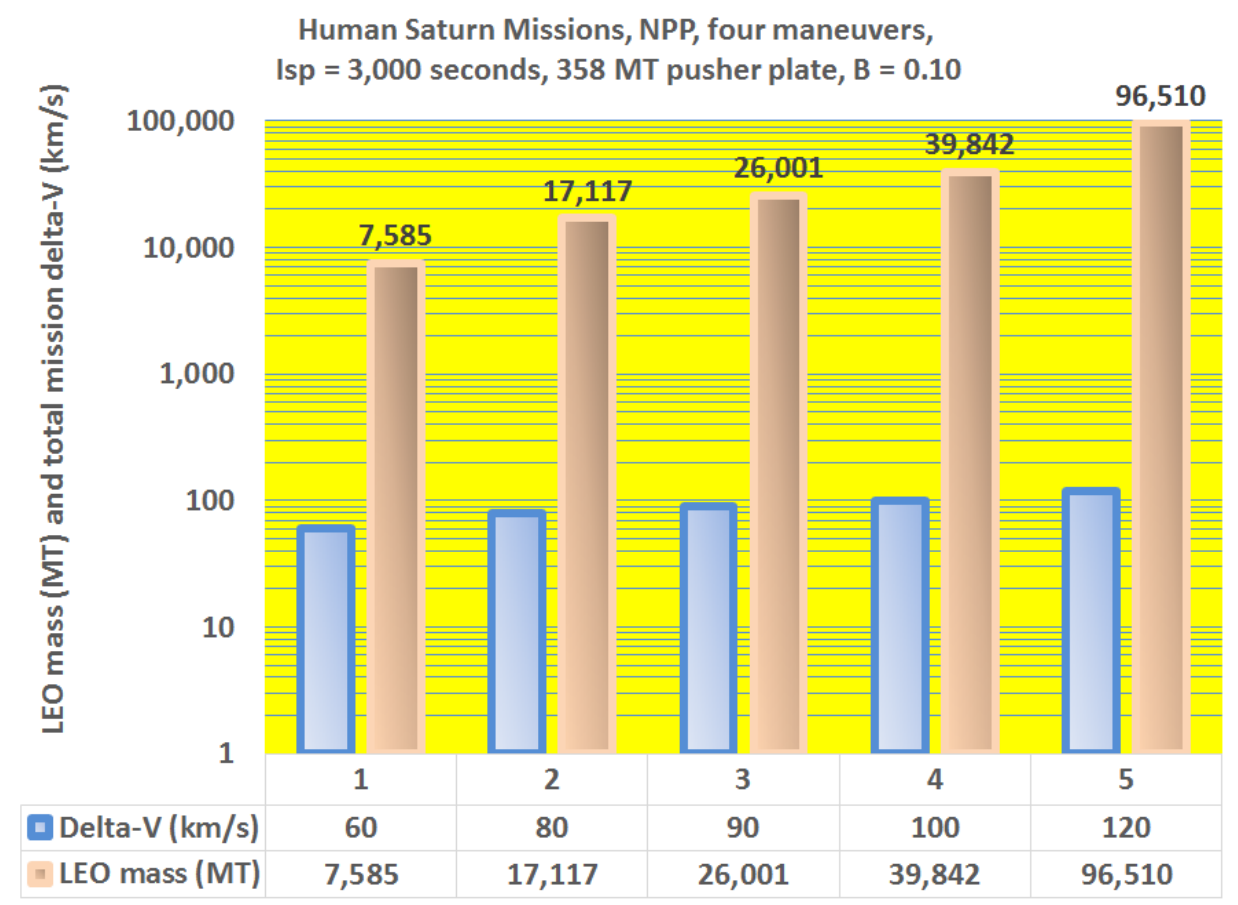

Figure 7. Saturn NPP sizing and mission data, $B=0.10 \mathrm{Mp}$ (Ref. 14).

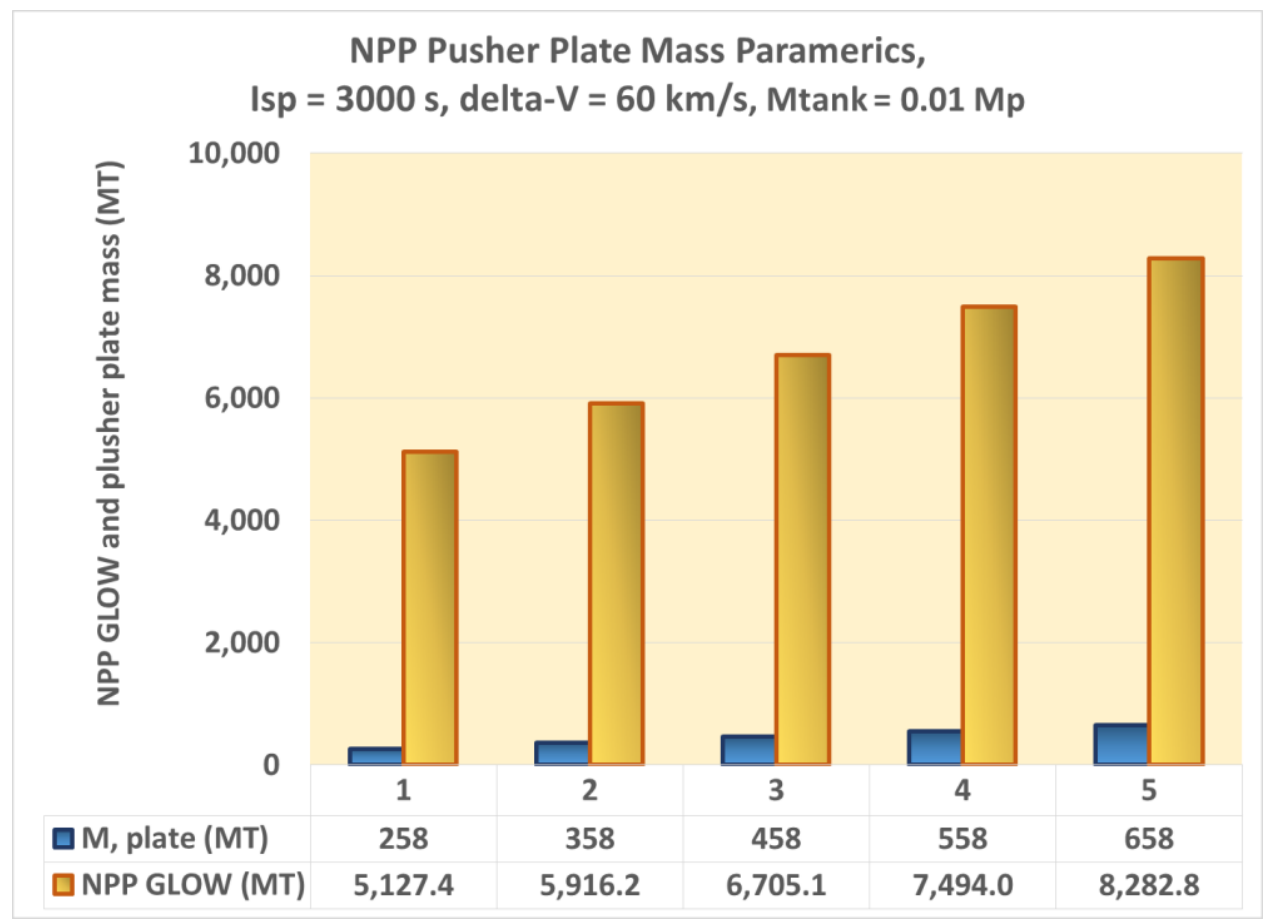

Figure 8. Saturn NPP sizing and mission data, B = 0.01 Mp, with pusher plate mass sensitivity. 


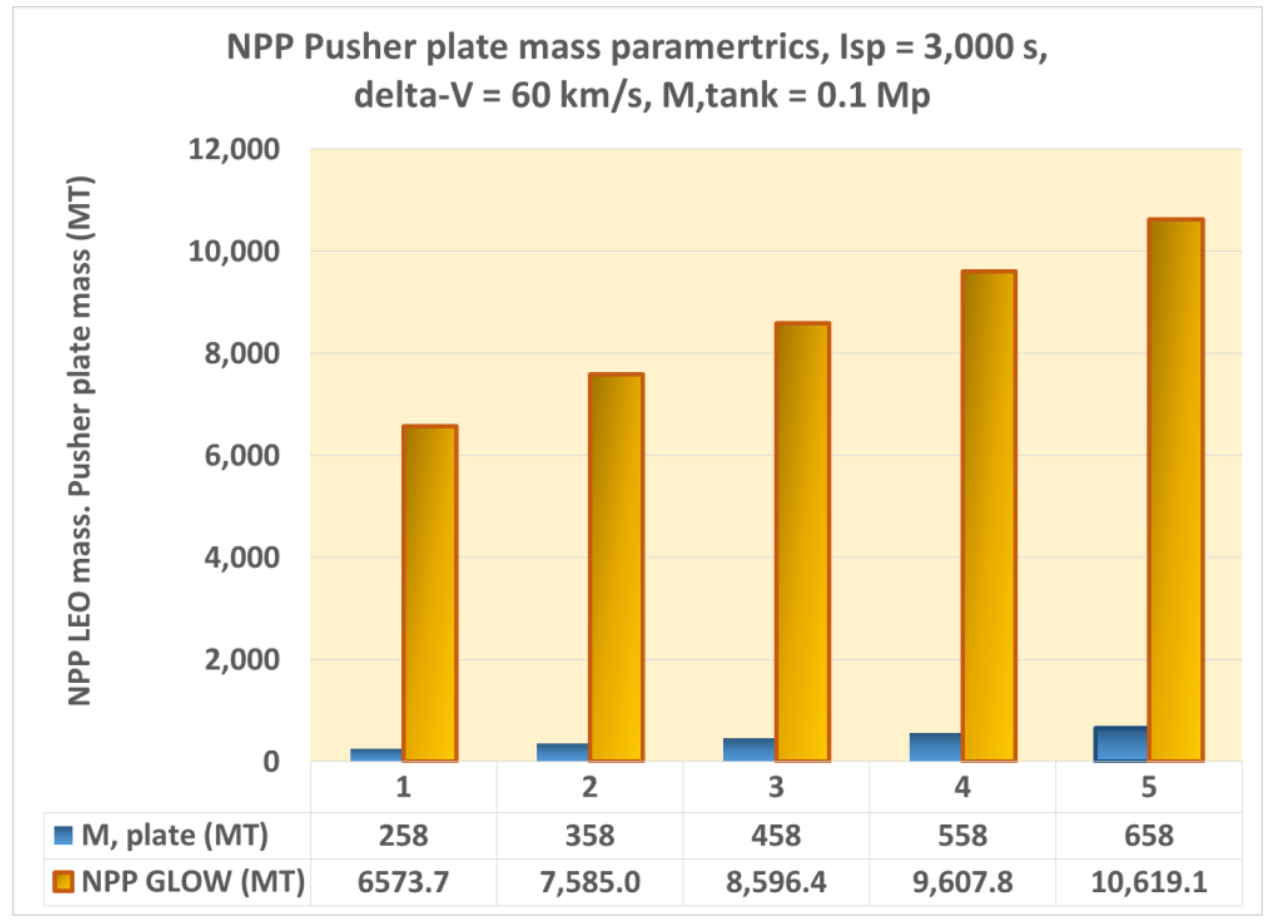

Figure 9. Saturn NPP sizing and mission data, B $=0.10 \mathrm{Mp}$, with pusher plate mass sensitivity.

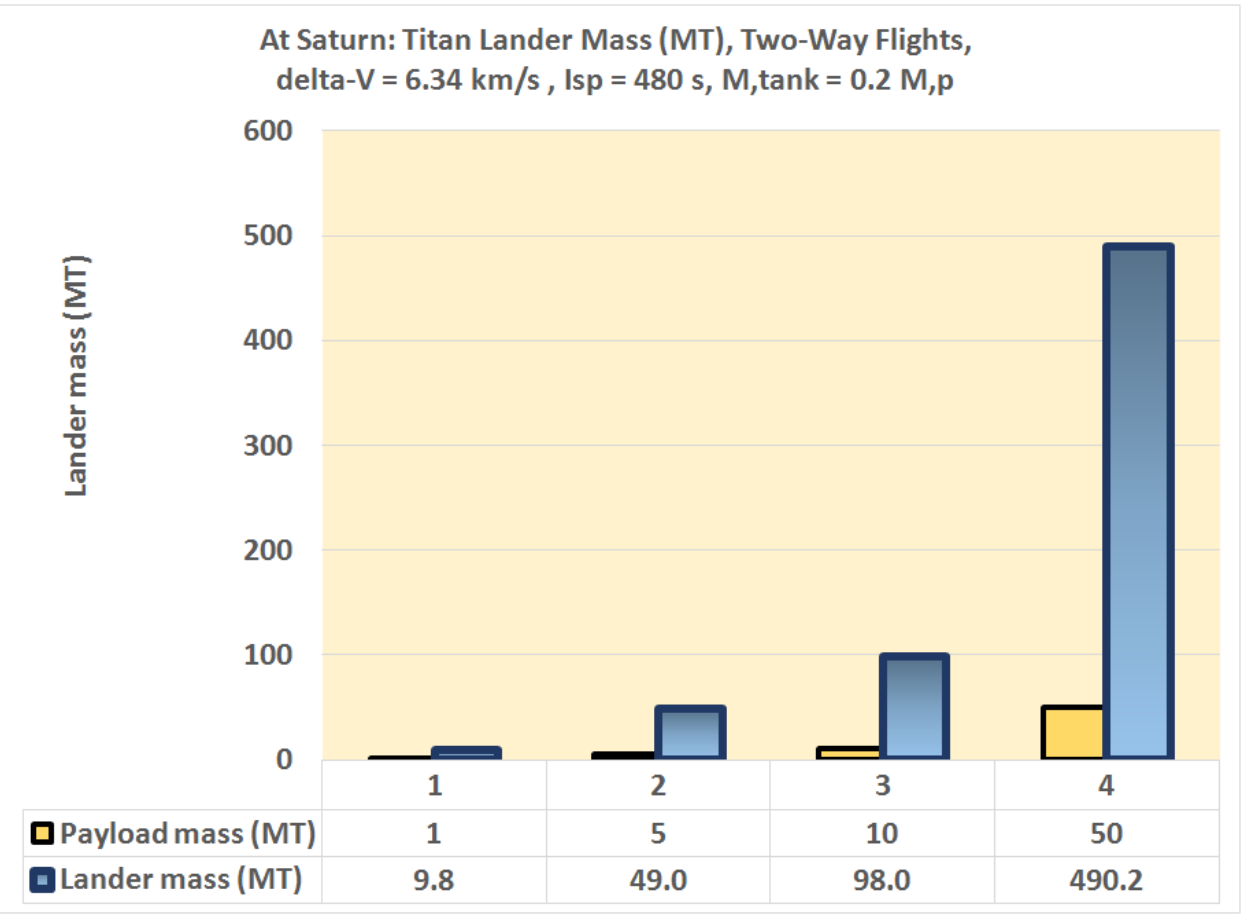

Figure 10. Saturn Moon Lander Mass for Titan, round trip flights, with payload masses of 1 to 50 MT. 


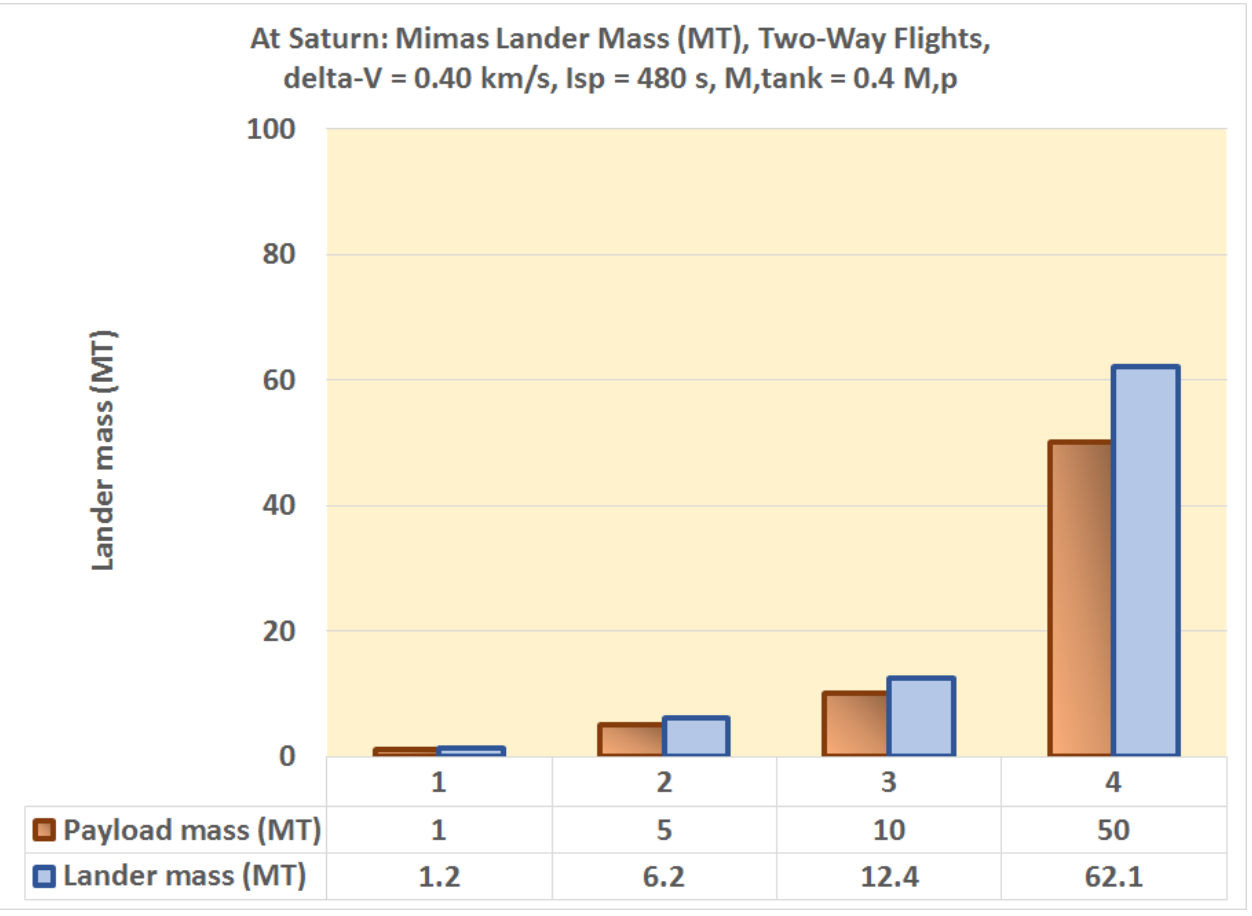

Figure 11. Saturn Moon Lander Mass for Mimas, round trip flights, with payload masses of 1 to 50 MT.

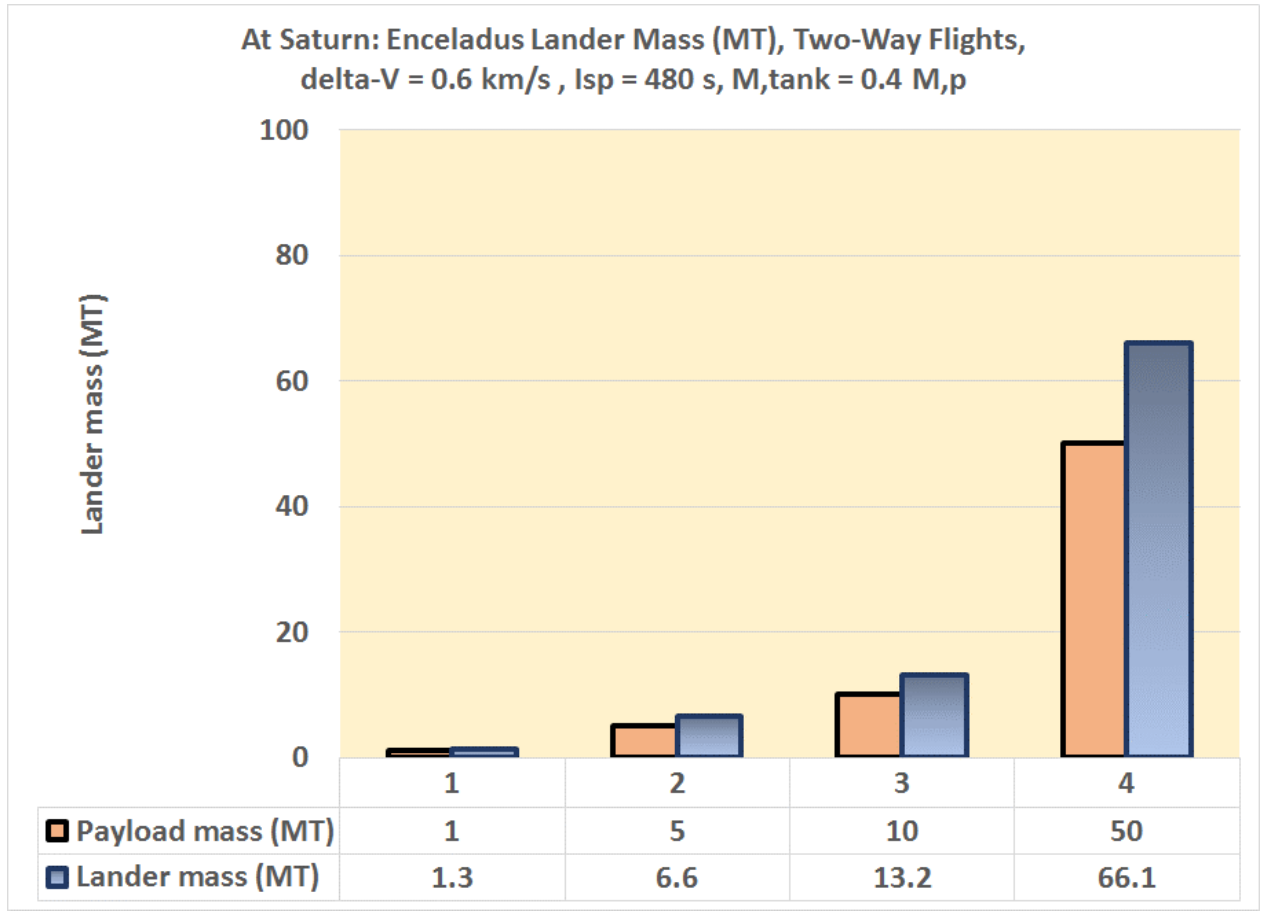

Figure 12. Saturn Moon Lander Mass for Enceladus, round trip flights, payload masses of 1 to 50 MT. 


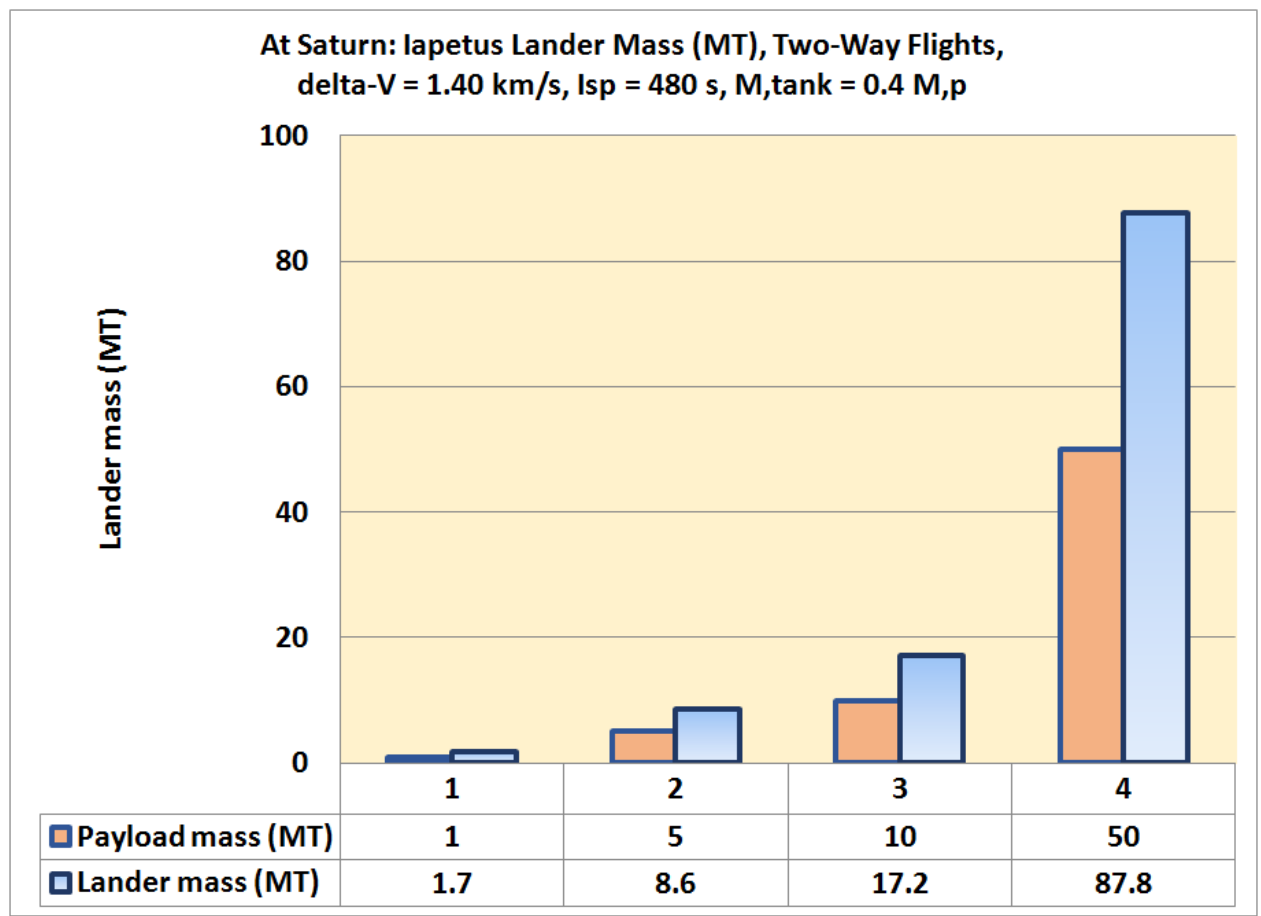

Figure 13. Saturn Moon Lander Mass for Iapetus, round trip flights, with payload masses of 1 to 50 MT.

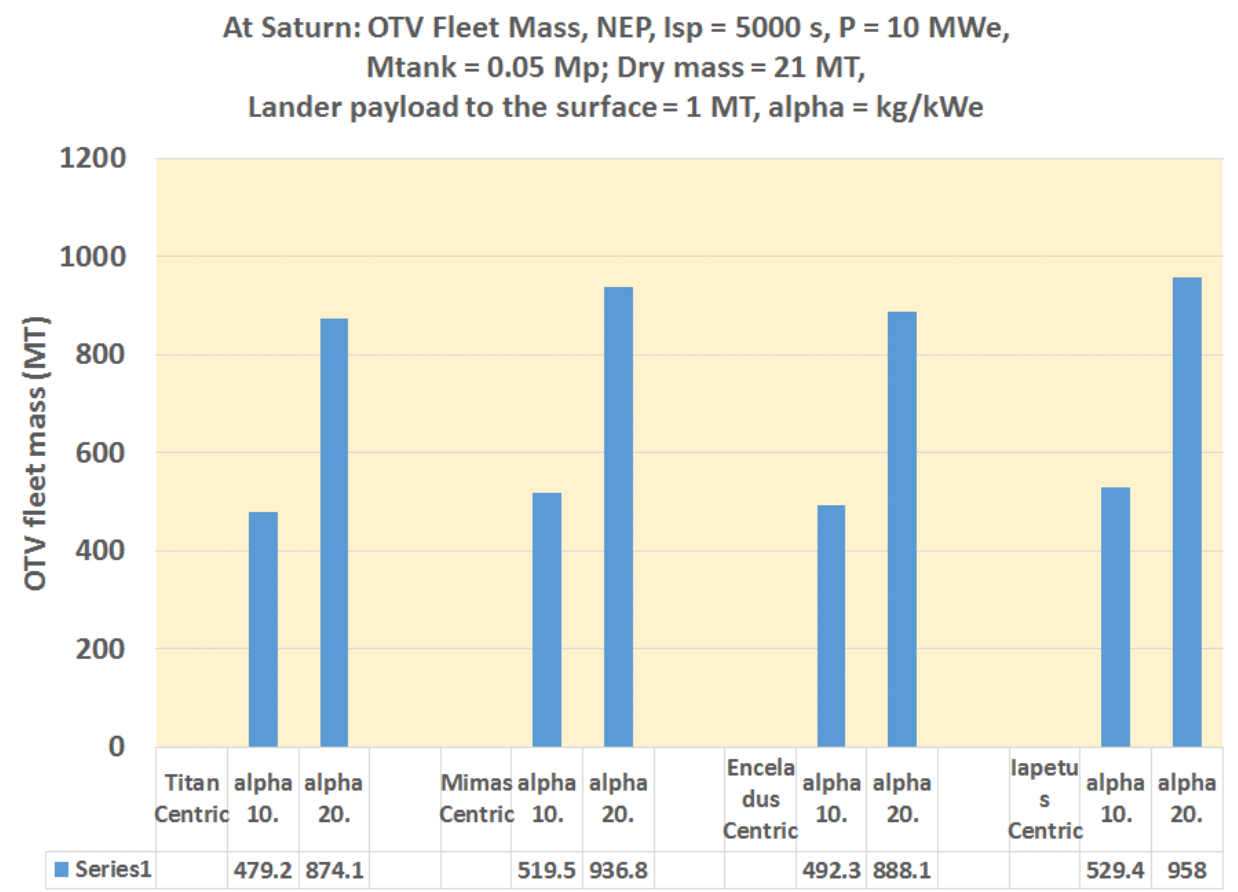

Figure 14. Saturn Moon OTV Fleet System Masses, round trip flights, with lander payload masses of 1 MT, for Titan. Mimas, Enceladus, and Iapetus. 